\title{
Pendeteksi Hemoglobin Non Invasive
}

\author{
Erika Wahyu Ningsih ${ }^{1}$, Hanifah Rahmi Fajrin*2, Aidatul Fitriyah ${ }^{3}$ \\ ${ }^{1,2}$ Universitas Muhammadiyah Yogyakarta, Indonesia \\ ${ }^{3}$ Rumah Sakit Akademik Universitas Gadjah Mada
}

INFO ARTIKEL

\begin{abstract}
Alamat Web Artikel:
Journal.umy.ac.id/index.php/
\end{abstract}

$\mathrm{mt} / \mathrm{article} / \mathrm{view} / 7256$

DOI:

https://doi.org/10.18196/mt.010102

\section{Data Artikel:}

Diterima:

19 Okt 2019

Direview:

21 Okt 2019

Direvisi:

24 Okt 2019

Disetujui:

31 Okt 2019

Korespondensi:

hanifah.fajrin@vokasi.umy.ac.id

\begin{abstract}
ABSTRAK
Anemia merupakan suatu kondisi medis dengan jumlah sel darah merah atau Hemoglobin $(\mathrm{Hb})$ kurang dari $12 \mathrm{~g} / \mathrm{dL}$. Pemeriksaan hemoglobin $(\mathrm{Hb})$ pada umumnya dilakukan dengan menggunakan metode invasive, akan tetapi metode ini terdapat beberapa kekurangan, diantaranya yaitu kurang efisien dan kurang ramah bagi para pasien yang mempunyai ketakutan terhadap jarum suntik. Penelitian ini bertujuan untuk membuat alat pendeteksi hemoglobin dalam darah dengan menggunakan metode non invasive dengan menggunkan infrared dan photodioda sebagai sensornya dan beberapa rangkaian elektronika lainnya sebagai pendukung. Dari hasil pengujian modul ini yang dibandingkan dengan EasyTouch GCHB, didapatkan simpangan maksimal yaitu $1 \mathrm{~g} / \mathrm{dl}$ dan minimal $0,1 \mathrm{~g} / \mathrm{dl}$, dan mempunyai error maksimal sebesar $6,4 \%$ dan minimal 0,8 $\%$ dan rata-rata error sebesar $0,1 \%$ yang berarti alat ini layak untuk digunakan karena nilai simpangan maksimal adalah $1 \mathrm{~g} / \mathrm{dl}$ dan toleransi dari hemoglobin adalah $1 \mathrm{~g} / \mathrm{dl}$.
\end{abstract}

Kata Kunci: Hemoglobin, Non Invasive, ATMega8

\section{PENDAHULUAN}

Hemoglobin memiliki peran penting untuk protein darah vital [1]. Hemoglobin merupakan pigmen yang membuat warna merah pada sel darah. Menurut fungsinya, Hemoglobin digunakan sebagai media transport oksigen dari paru-paru ke jaringan tubuh. Oksigen adalah suatu bagian terpenting dari metabolisme tubuh untuk menghasilkan energi. Hemoglobin juga mempunyai fungsi membawa Karbondioksida hasil metabolisme dari jaringan tubuh ke paru paru untuk selanjutnya dikeluarkan saat bernafas [2].

Penyakit yang berhubungan dengan kadar hemoglobin dalam darah yaitu anemia. Anemia adalah masalah kesehatan masyarakat di negara berkembang. Prevalensi anemia tinggi dalam 1 sampai 5 tahun anak dalam perkembangan [3]. Sebagian besar anemia di Indonesia disebabkan oleh kekurangan zat besi. Kelompok masyarakat yang rawan terkena anemia adalah anak-anak, remaja, ibu hamil dan menyusui serta pekerja berpenghasilan [4]. Anemia adalah penyakit kurang darah yang sebagian besar disebabkan oleh konsumsi makan yang dimakan kurang mengandung besi.

Pengukuran nilai $\mathrm{Hb}$ biasanya dilakukan secara invasive yaitu dengan mengambil sampel darah, sampel darah yang telah diambil melihat intensitas warna dari sampel yang telah diberi reagen. Pengukuran intensitas warna dilakukan dengan metode sahli (metode manual), maupun dengan metode Sianmethemoglobin (dengan spektrofotometer) [5].

Namun, cara tersebut kurang efesien dikarenakan menyebabkan rasa sakit pada pasien dikarenakan pengambilan sampel darah dilakukan dengan cara melukai salah satu jari pasien, dan prosesnya sedikit lebih lama dikarenakan hasil dari pengukuran $\mathrm{Hb}$ dicatat, dikumpulkan, direkapitulasi di komputer.

Supriatna Adhisuwignjo dari Politeknik Negeri Malang meneliti tentang pemanfaatan sensor cahaya sebagai alat untuk mengukur kadar hemoglobin dalam darah. Sistem pengukuran menggunakan sensor LDR (Light Dependent Resistor), berdasarkan perbedaan kepekatan warna darah manusia. Menggunakan AT89S51 untuk memproses data dan menggunakan Liquid Crystal 


\author{
Ningsih, Fajrin, Fitriyah \\ Pendeteksi Hemoglobin Non Invasive
}

Display (LCD) untuk menampilkan hasil pengukuran. Pada penelitian ini hasil akan di tampilkan pada Liquid Crystal Display (LCD) dalam bentuk gr \%, nilai yang ditampilkan pada LCD disesuaikan berdasarkan hemoglobin sahli. Pada penelitian ini juga dijelaskan bahwa sensor yang digunakan kurang peka dengan warna [6].

Dengan ini penulis bermaksud merancang alat pemeriksa hemoglobin dalam darah dengan metode non invasive (tanpa melukai tubuh pasien), metode ini digunakan agar pasien tidak merasakan rasa sakit pada saat pemeriksaan $\mathrm{Hb}$, karena pemeriksaan hanya meletakan sensor/ tranduser optik pada permukaan kulit. Pemeriksaan dengan cara non invasive juga dapat menghindari kontaminasi bakteri, dan hasilnya dapat langsung diketahui dengan tampilan LCD, hasil analisis yang didapat langsung ditampilkan, sehingga pasien dapat mengatahui secara langsung.

Penyakit yang berhubungan dengan kadar hemoglobin dalam darah yaitu anemia. Anemia adalah masalah kesehatan masyarakat di negara berkembang. Prevalensi anemia tinggi dalam 1 sampai 5 tahun anak dalam perkembangan [3]. Sebagian besar anemia di Indonesia disebabkan oleh kekurangan zat besi. Kelompok masyarakat yang rawan terkena anemia adalah anak-anak, remaja, ibu hamil dan menyusui serta pekerja berpenghasilan [4]. Anemia adalah penyakit kurang darah yang sebagian besar disebabkan oleh konsumsi makan yang dimakan kurang mengandung besi.

\title{
2. METODE PENELITIAN
}

Metode yang dilakukan dalam penelitian ini terdiri dari beberapa tahap, yaitu perancangan hardware dan perancangan software.

\subsection{Perancangan Hardware}

Perancangan hardware pada modul menggunakan beberapa modul rangkaian diantaranya adalah rangkaian system minimum microcontroller ATMega 8, sedangkan perangkat lunak yang digunakan adalah CVAVR.

\subsubsection{Rangkaian Minimum Sistem}

Rangkaian minimum sistem digunakan sebagai otak pengendali aktivitas yang ada pada alat. Rangkaian minimum sistem menggunakan ATMega 8 yang dilengkapi dengan ADC internal sehingga mempermudah sistem converter. Pada rangkaian minimum sistem terdapat juga port downloader yang mempunyai fungsi memasukan program yang dibutuhkan. Di dalam rangkaian terdapat kapasitor $100 \mathrm{nF}$ yang terhubung dengan port VCC dan ground, terdapat kapasitor $100 \mathrm{nF}$ yang dihubungkan ke tombol reset dan di rangkai seri dengan resistor $4 \mathrm{k} 7 \Omega$ yang masuk ke PORTC6/Reset. Pada PORTB 6 dan PORTB 7 terhubung dengan kapasitor 22 pF yang terhubung dengan Crystal 16 MHz. Rangkaian Minimum Sistem dapat dilihat pada Gambar 1.

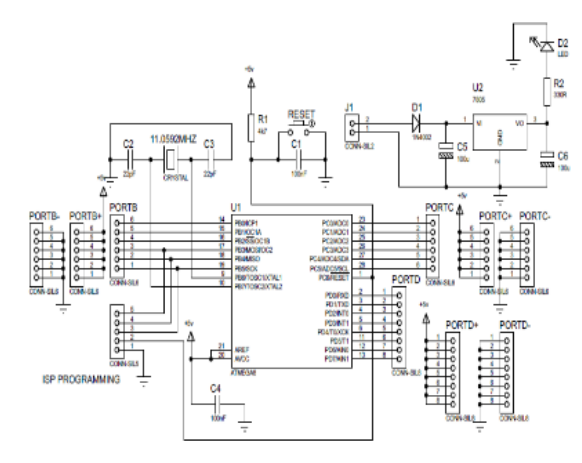

Gambar 1 Rangkaian Minimun Sistem 


\section{Ningsih, Fajrin, Fitriyah}

Pendeteksi Hemoglobin Non Invasive

\subsubsection{Rangkaian LCD}

Gambar rangkaian LCD dapat dilihat pada Gambar 2.

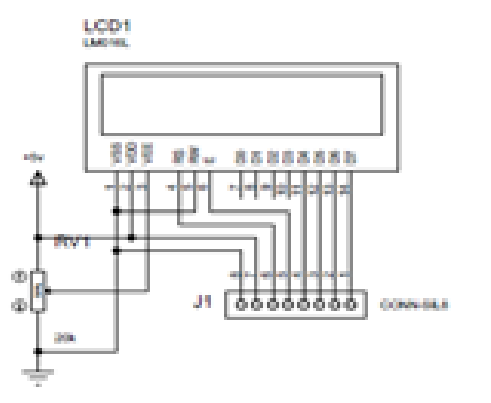

Gambar 2 Rangkaian LCD 2 X 16

Tampilan output berupa LCD dengan menggunakan LCD karakter $2 \times 16$, diperlukan tegangan supply sebesar $5 \mathrm{~V}$ untuk dapat menyalakan LCD dari pin VDD dan ground dari pin VSS dan pengaturan kontras kecerahan LCD dipasang resistor variabel dengan tegangan input $5 \mathrm{~V}$, nilai resistor yang digunakan adalah sebesar $20 \mathrm{~K} \Omega$. LCD mendapatkan PORT D pada ATMega8 D7 mendapatkan PORTD 5, D6 mendapatkan PORTD4, D5 mendapatkan PORTD3, D4 mendapatkan PORTD2.

\subsubsection{Rangkaian Sensor}

Gambar rangkaian sensor dapat dilihat pada Gambar 3

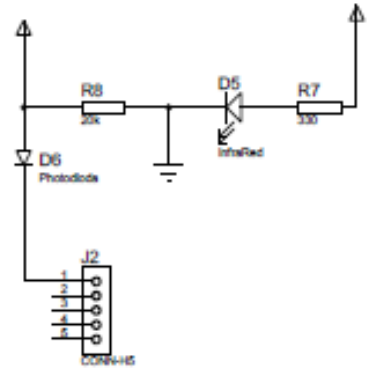

Gambar 3 Rangkaian Sensor

Rangkaian sensor menggunakan infrared dan photodioda, infrared akan memancarkan cahaya dan akan diterima oleh photodiode.

Kaki output photodiode akan masuk ke mikrokontroler yaitu ke PORTC 1. Photodiode yang menerima cahaya infrared masih berupa resistansi sehingga dipasang resistor $10 \mathrm{k} \Omega$ sebagai pembagi tegangan agar resistansi pada photodioda berubah menjadi orde volt.

\subsubsection{Rangkaian Sensor Pembagi Tegangan}

Gambar Rangkaian pembagi tegangan ditunjukan pada Gambar 4

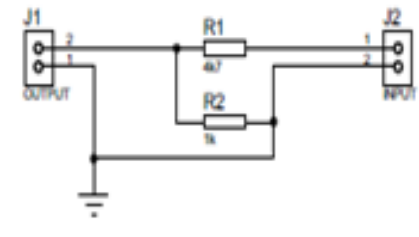

Gambar 4 Rangkaian Sensor Pembagi Tegangan

Medika Teknika : Jurnal Teknik Elektromedik Indonesia, Vol 01 No. 1, Oktober 2019|9 


\section{Ningsih, Fajrin, Fitriyah \\ Pendeteksi Hemoglobin Non Invasive}

Rangkaian pembagi tegangan mempunyai tugas untuk membagi tegangan. Rangkaian pembagi tegangan ini juga digunakan untuk membaca baterai pada LCD. Rangkaian pembagi tegangan ini memiliki fungsi yaitu mengubah tegangan besar menjadi tegangan yang lebih kecil dengan memanfaatkan dua resistor yang dirangkai seri.

\subsection{Perancangan Software}

Perangkat lunak pada alat untuk memproses sinyal yang didapat dari sensor menggunakan CVAVR microcontroller sebagai pengolah data. Software pemrograman CVAVR sebagai pengolah data pada alat. Sensor yang digunakan pada pembuatan alat adalah Infrared dan Photodiode untuk pemeriksaan hemoglobin.

Diagram alir sistem dapat dilihat pada Gambar 5

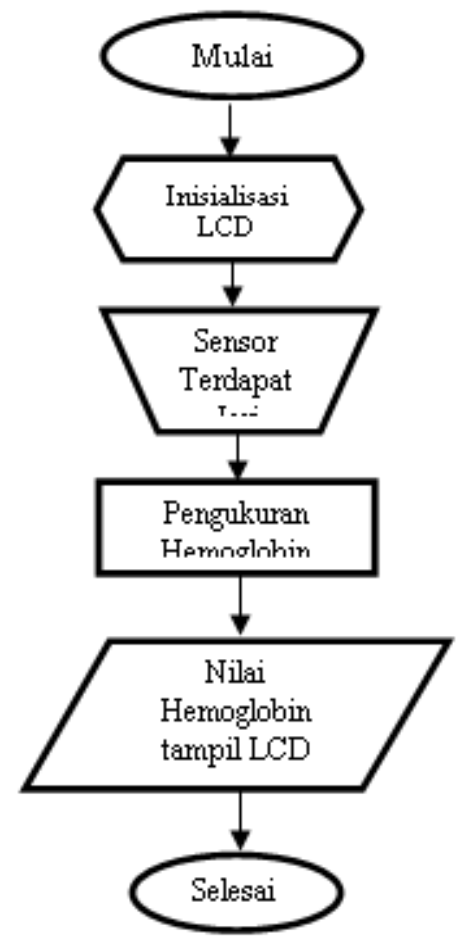

Gambar 5 Diagram Alir Proses

Saat alat dihidupkan, program memulai proses inisialisasi. Inisialisasi bertujuan agar program berjalan sesuai dengan perintah. Ambil data diatas bermaksud infrared dan Photodiode bekerja secara bergantian. Sensor terdapat jari bertujuan untuk memasukan input ke program dengan cara meletakan jari pada sensor, cahaya yang dipancarkan oleh infrared akan diserap oleh jari mengakibatkan adanya sinyal dan akan diterima oleh photodiode. Apabila tidak terdapat jari pada sensor maka nilai kadar hemoglobin tidak akan ditampilkan pada LCD. Sinyal akan dihitung atau diolah untuk mencari nilai dari kadar hemoglobin. Nilai hemoglobin akan ditampilkan pada LCD, akan tertampil indikasi "NORMAL" apabila kadar hemoglobin di dalam range 12-15 g/dl, akan tertampil "LOW" apabila kadar hemoglobin $<12 \mathrm{~g} / \mathrm{dl}$ dan akan tertampil "HIGH" apabila kadar hemoglobin $>15 \mathrm{~g} / \mathrm{dl}$.

\section{HASIL DAN PEMBAHASAN}

Pada penelitian ini, melakukan pengujian modul dengan dua cara pengujian yaitu pengujian test point dan pengujian perbandingan modul dengan pembanding. Bagian pertama pengujian test point. 


\section{Ningsih, Fajrin, Fitriyah}

Pendeteksi Hemoglobin Non Invasive

\subsection{Hasil Pengukuran Responden}

Hasil pengukuran responden dilakukan dengan melakukan pengujian menggunakan alat pembanding yaitu EasyTouch GCHB dan dibandingkan dengan modul. Hasil pengukuran dari responden menggunakan metode invasive dan non invasive ditunjukan Tabel 1.

Tabel 1 Hasil Pengujian

\begin{tabular}{|c|c|c|c|}
\hline Responden & GCHB & Indikasi & $\begin{array}{c}\text { Terbaca } \\
\text { modul }\end{array}$ \\
\hline $\begin{array}{c}\text { Erika } \\
(20)\end{array}$ & $\begin{array}{l}13,2 \\
\mathrm{~g} / \mathrm{dl}\end{array}$ & Normal & $13,1 \mathrm{~g} / \mathrm{dl}$ \\
\hline $\begin{array}{c}\text { Riska } \\
(21)\end{array}$ & $\begin{array}{l}14,1 \\
\mathrm{~g} / \mathrm{dl}\end{array}$ & Normal & $14,7 \mathrm{~g} / \mathrm{dl}$ \\
\hline $\begin{array}{c}\text { Ari } \\
(22)\end{array}$ & $\begin{array}{l}12,7 \\
\mathrm{~g} / \mathrm{dl}\end{array}$ & Normal & $13,0 \mathrm{~g} / \mathrm{dl}$ \\
\hline $\begin{array}{c}\text { Adi } \\
(20)\end{array}$ & $\begin{array}{l}15,7 \\
\mathrm{~g} / \mathrm{dl}\end{array}$ & Normal & $15,0 \mathrm{~g} / \mathrm{dl}$ \\
\hline $\begin{array}{c}\text { Tiyas } \\
(21)\end{array}$ & $\begin{array}{l}15,6 \\
\mathrm{~g} / \mathrm{dl}\end{array}$ & Normal & $14,6 \mathrm{~g} / \mathrm{dl}$ \\
\hline $\begin{array}{c}\text { Hana } \\
(21)\end{array}$ & $\begin{array}{c}12,8 \\
\mathrm{~g} / \mathrm{dl}\end{array}$ & Normal & $12,9 \mathrm{~g} / \mathrm{dl}$ \\
\hline $\begin{array}{c}\text { Ola } \\
(21)\end{array}$ & $\begin{array}{l}12,8 \\
\mathrm{~g} / \mathrm{dl}\end{array}$ & Normal & $13,1 \mathrm{~g} / \mathrm{dl}$ \\
\hline $\begin{array}{c}\text { Rahmat } \\
(21)\end{array}$ & $\begin{array}{l}14,5 \\
\mathrm{~g} / \mathrm{dl}\end{array}$ & Normal & $14,2 \mathrm{~g} / \mathrm{dl}$ \\
\hline $\begin{array}{c}\text { Nindy } \\
(21)\end{array}$ & $\begin{array}{l}11,5 \\
\mathrm{~g} / \mathrm{dl}\end{array}$ & Low & $11,6 \mathrm{~g} / \mathrm{dl}$ \\
\hline $\begin{array}{c}\text { Gesta } \\
(20)\end{array}$ & $\begin{array}{l}10,8 \\
\mathrm{~g} / \mathrm{dl}\end{array}$ & Low & $11,2 \mathrm{~g} / \mathrm{dl}$ \\
\hline
\end{tabular}

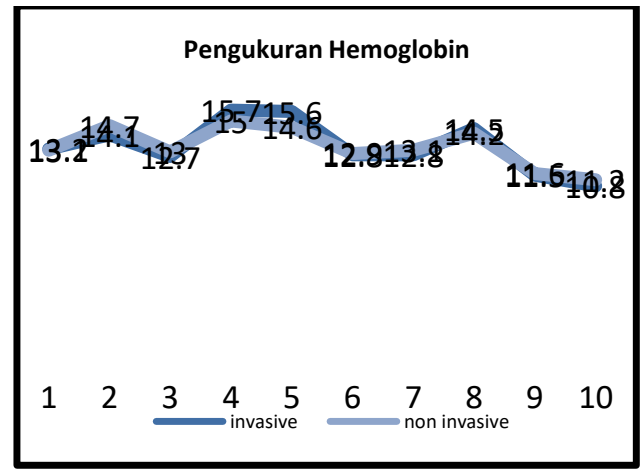

Gambar 6 Grafik Pengukuran Hemoglobin

Hasil pengukuran hemoglobin pada pengukuran responden pertama mendapatkan hasil hemoglobin 13,2 g/dl dengan indikasi normal memdapatkan rata-rata sebesar 13,1 g/dl dan terbaca pada modul juga normal. Kemudiam responden yang kedua pengukuran hemoglobin menggunakan pembanding dan mendapatkan hasil pengukuran sebesar 14,1 g/dl dengan indikasi normal dan ratarata sebesar $14,7 \mathrm{~g} / \mathrm{dl}$ terbaca pada modul juga normal. Pada pengukuran ketiga didapatkan hasil pengukuran sebesar 12,7 g/dl dengan indikasi normal dengan rata-rata 13,0 g/dl dan terbaca pada modul adalah Normal. Pada pengukuran ke 4 didapatkan hasil pengukuran sebesar 15,7 g/dl dengan indikasi High dan mendapatkan rata-rata sebesar 15,0 terbaca pada modul adalah Normal. Hal ini dapat dikarenakan peletakan jari tangan di sensor atau sensor mendapatkan goncangan. 


\author{
Ningsih, Fajrin, Fitriyah \\ Pendeteksi Hemoglobin Non Invasive
}

Pada pengukuran pada responden kelima mendapatkan hasil pengukuran 15,6 g/dl dengan indikasi High dan rata-rata sebesar 14,6 g/dl terbaca pada modul Normal. Pada pengukuran pada responden ke 6 dan 7 dengan hasil 12,8 g/dl dengan indikasi normal tetapi memiliki rata-rata yang berbeda pada responden yang ke 6 memiliki rata-rata 12,9 terbaca pada modul normal $\mathrm{g} / \mathrm{dl}$ dan responden ke 7 memiliki rata-rata sebesar $13,1 \mathrm{~g} / \mathrm{dl}$ terbaca modul normal. Kemudian data dari responden ke 8 mendapatkan hasil 14,5 g/dl dengan indikasi normal dan memdapatkan rata-rata sebesar 14,2 g/dl terbaca pada modul normal. Pada pengukuran responden ke sembilan mendapatkan hasil pengukuran sebesar 11,8 g/dl dengan indikasi low dan mendapatkan nilai rata-rata sebesar 11,6 $\mathrm{g} / \mathrm{dl}$ terbaca pada modul low dan pengukuran pada responden 10 mendapatkan hasil sebesar 10,8 g/dl dengan indikai low dan mendapatkan rata-rata sebesar 11,2 g/dl terbaca pada modul low.

\title{
4. KESIMPULAN
}

Berdasarkan pengukuran dan pengujian dapat dikatakan modul dapat berfungsi, tetapi masih terdapat pembacaan yang berbeda dengan alat pembanding. Error yang didapatkan cukup kecil. Dari 10 kali pengujian didapatkan hasil error yang terbesar adalah 6,4 \% dan nilai error yang terkecil adalah 0,8\% dan Simpangan yang didapatkan dari alat ini kurang lebih sekitar $1 \mathrm{~g} / \mathrm{dl}$. Pembacaan indikasi pada LCD juga sudah sesuai dengan nilai kadar hemoglobin.

\section{DAFTAR PUSTAKA}

[1] S. Qureshi, S. A. Memon, A. B. Ghanghro, and M. F. Qureshi, "Hemoglobin adducts in paint industry workers," Adv. Life Sci., vol. 1, no. 4, pp. 208-216, 2014.

[2] N. Herawati, "Mengenal Anemia dan Peranan Erythropoietin," BioTrends, vol. 4, no. 1, pp. 35-39, 2009.

[3] T. Nadu, "Anemia in Toddlers of Kattankulathur, Kancheepuram District," Int. J. Pharma Bio Sci., vol. 3, no. 1, pp. 687-692, 2012.

[4] Sunita Almatsier, Prinsip Dasar Ilmu Gizi. Jakarta: Gramedia Pustaka Utama, 2003.

[5] A. Muhammad, "Rancang Bangun Sistem Pengukuran Kadar Hemoglobin Darah Berbasis Mikrokontroler," Universitas Airlangga, 2012.

[6] S. Adhisuwignjo, "Pemanfaatan Sensor Cahaya Sebagai Alat Untuk Mengukur Kadar Hemoglobin Dalam Darah," Politeknik Negeri Malang, 2016. 